\title{
Hypernatraemia due to a reset osmostat for vasopressin release and thirst, complicated by nephrogenic diabetes insipidus
}

\author{
C.J. Thompson, J. Freeman, C.O. Record and P.H. Baylis \\ Department of Medicine, Royal Victoria Infirmary, Newcastle upon Tyne NE1 4LP, UK.
}

\begin{abstract}
Summary: We describe a patient with chronic hypernatraemia (plasma sodium 148-155 mmol/l) and partial nephrogenic diabetes insipidus who had received prolonged lithium treatment. Despite stopping the drug for one year the abnormalities remained. Infusion of hypertonic saline $(\mathrm{NaCl} 855 \mathrm{mmol} / \mathrm{l})$ allowed the characterization of osmoregulation of thirst and vasopressin secretion. Linear regression analysis of plasma vasopressin and osmolality defined the function, $\mathrm{pAVP}=0.27(\mathrm{pOsm}-301)$, and analysis of thirst measured by a visual analogue scale and plasma osmolality, the function, thirst $=0.16$ (pOsm-302) where PAVP and pOsm represent plasma arginine vasopressin and osmolality respectively. The slopes of the regression lines which describe the sensitivity of the osmoreceptors were within the normal range, but both abscissal intercepts, which define the thresholds for vasopressin release and thirst, were markedly elevated in comparison to normal (upper limit $<290 \mathrm{mOsm} / \mathrm{kg}$ ). Other investigations of electrolytes, anterior pituitary function and high definition computed tomographic scanning of hypothalamo-pituitary region were all normal.

We conclude that this patient's chronic hypernatraemia was due to resetting of the osmostats for both vasopressin release and thirst, a rarely described mechanism to account for hypernatraemia. Although it is probable that the partial nephrogenic diabetes insipidus was related to prolonged lithium therapy, the cause of the reset osmostats remains unclear.
\end{abstract}

\section{Introduction}

Although a rare syndrome, chronic essential hypernatraemia has been recognized for a number of years. $^{1-8}$ The mechanisms responsible for the syndrome are poorly understood, and until recently the putative abnormalities of vasopressin secretion could only be inferred from indirect assessments of vasopressin action. It now appears that different patterns of osmoregulated vasopressin release and hypodipsia can lead to chronic hypernatraemia. A reduction in vasopressin release in response to hyperosmolality combined with decreased thirst sensation is only one mechanism that accounts for chronic hypernatraemia;' hypodipsia with normal osmoregulated vasopressin release $^{10}$ and a reset osmostat for vasopressin release ${ }^{8}$ have also been described.

In this report we describe a hypodipsic hypernatraemic patient who demonstrated a shift in the osmotic threshold for vasopressin secretion and thirst to a plasma osmolality higher than normal but who otherwise had normal osmoregulated vasopressin

Correspondence: C.J. Thompson M.B., M.R.C.P., Endocrine Unit, Royal Victoria Infirmary, Newcastle upon Tyne NE1 4LP, UK.

Accepted: 2 June 1987 release. The clinical situation was complicated by nephrogenic diabetes insipidus which was probably related to prolonged lithium therapy. Whether the disorder of vasopressin osmoregulation was due to lithium therapy remains speculative.

\section{Case report}

A 65 year old woman who had treated autoimmune hypothyroidism (1-thyroxine $75 \mu \mathrm{g} /$ day), hypertension (atenolol $50 \mathrm{mg} /$ day) and mild non-insulin dependent diabetes mellitus, was admitted with acute cholangitis. Her manic depressive psychosis had been treated with lithium carbonate $800 \mathrm{mg} /$ day and imipramine $75 \mathrm{mg} /$ day for many years. The acute infective illness was successfully treated with antibiotics and extensive investigations including endoscopic retrograde- cholangiopancreatography were unremarkable.

During her illness and the convalescent period it was noted that she had persistent hypernatraemia, plasma sodium 148-155 mmol/l (normal range 137-145) and was hypertonic, plasma osmolality 305-321 mOsm/ kg (normal range 282-298). Despite hypertonic 
hypernatraemia she denied feeling thirsty. Intravenous fluids ( $5 \%$ dextrose and physiological saline) were given to treat dehydration and lower plasma sodium but as plasma sodium approached normal values she developed polyuria, urine volume ranging from 3.86.2 litres $/ 24 \mathrm{~h}$. Control of diabetes mellitus by diet alone was good, fasting blood glucose less than $6.0 \mathrm{mmol} / \mathrm{l}$, glycosylated haemoglobin $6.8 \%$ (normal range 5.0-7.5), and no glycosuria. Plasma calcium was $2.24 \mathrm{mmol} / \mathrm{l}$ (normal range $2.12-2.62$ ), potassium $4.2 \mathrm{mmol} / 1$ (normal range 3.1-4.4), and urea $9.3 \mathrm{mmol} / 1$ (normal range $2.1-6.3$ ).

When she had recovered from her acute illness, posterior pituitary function, thirst and renal concentrating ability were studied (for details see below). Investigations of anterior pituitary function and other endocrine tests were also performed. Serum thyroxine was $108 \mathrm{nmol} / 1$ (normal range 63-131), triiodothyronine $1.5 \mathrm{nmol} / 1$ (normal range $1.2-3.0$ ), thyrotrophin $8.4 \mathrm{mU} / 1$ (normal range $<6.0$ ). Basal prolactin was normal $(<450 \mathrm{mU} / \mathrm{l})$ and gonadotrophins elevated in the post-menopausal range (luteinising hormone $>50 \mathrm{U} / \mathrm{l} ;$ follicle-stimulating hormone $>40 \mathrm{U} / \mathrm{l})$. There was normal diurnal variation in plasma cortisol $(09.00 \mathrm{~h} 236 \mathrm{nmol} / 1,12.00 \mathrm{~h} 114 \mathrm{nmol} / \mathrm{l})$. Stress tests of anterior pituitary function were not performed. Thyroid microsomal antibodies were positive (1:1600). Radiographs of the pituitary fossa were normal and high definition computed tomographic (CT) scan showed generalized cerebral atrophy but no focal abnormality in the region of the hypothalamus or pituitary.

Lithium therapy was stopped. She was given a therapeutic trial of thiazide diuretic to improve the nephrogenic diabetes insipidus, but without significant effect. She remained hypodipsic and slightly polyuric. She was instructed to maintain an oral fluid intake of at least 2.0 litres $/ 24 \mathrm{~h}$ and $0.51 / 24 \mathrm{~h}$ greater than urine output, irrespective of hypodipsia. Plasma sodium concentrations remained slightly elevated at $146-148 \mathrm{mmol} / \mathrm{l}$.

Investigations of posterior pituitary function, thirst and renal concentrating ability were repeated one year after initial studies (for results see below).

\section{Methods}

\section{Posterior pituitary function and thirst}

Osmoregulated vasopressin secretion and thirst stimulation were studied during infusion of hypertonic saline (sodium chloride $855 \mathrm{mmol} / \mathrm{l}$ ) according to a well established protocol. ${ }^{11}$ After an overnight fast but free access to water, hypertonic saline was infused at a rate of $0.06 \mathrm{ml} / \mathrm{kg} / \mathrm{min}$ for 2 hours during which time blood was drawn at regular intervals to measure plasma osmolality and plasma vasopressin. Thirst was assessed during infusion using an established visual analogue method..$^{12}$ Plasma vasopressin was measured by a specific and sensitive radioimmunoassay ${ }^{13}$ limit of detection $0.3 \mathrm{pmol}$ vasopressin/plasma, intra- and inter-assay coefficients of variation $9.7 \%$ and $15.3 \%$, respectively. Osmolality was determined by the depression of freezing point method (Advanced Instruments Osmometer, Model AD 3R; coefficient of variation $0.3 \%$ at osmolality $276 \mathrm{mOsm} / \mathrm{kg}$ ).

\section{Renal concentrating ability}

After overnight fast but free access to water, urine was collected and blood drawn to measure plasma osmolality. Thereafter, the $\mathrm{V}_{2}$-agonist desmopressin $2 \mu \mathrm{g}$ was administered i.m. and urine collection made at 3, 7 and $24 \mathrm{~h}$ after injection. On the following day high-dose desmopressin $(20 \mu \mathrm{g})$ was given and a similar urine collection made.

\section{Results}

The patient's results of hypertonic saline infusion in

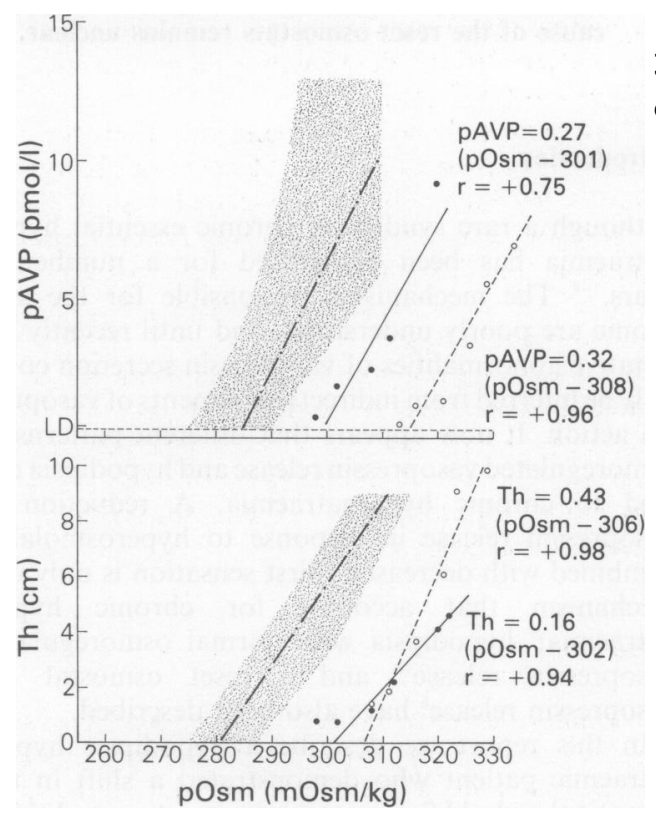

Figure 1 Responses of plasma arginine vasopressin (pAVP) and thirst (Th) to progressive increases in plasma osmolality (pOsm) induced by infusion of hypertonic saline, at the time of diagnosis $(\Theta)$ and one year later $(O)$. The lines represent the calculated regression lines, and the shaded areas the normal response with mean regression lines $(-\cdot-\cdot)$ defined by the functions pAVP $=0.41$ (pOsm-285) and $\mathrm{Th}=0.30(\mathrm{pOsm}-281)$. 
Table 1 Plasma and urine osmolality responses to the $V_{2}$-agonist desmopressin in $\mathrm{mOsm} / \mathrm{kg}$.

\begin{tabular}{|c|c|c|c|c|}
\hline \multirow[b]{2}{*}{ Time } & \multicolumn{2}{|c|}{ Initial study } & \multicolumn{2}{|c|}{ Study after one year } \\
\hline & pOsm & $\mu O s m$ & pOsm & $\mu O s m$ \\
\hline \multicolumn{5}{|l|}{ Day 1} \\
\hline Basal & 311 & 209 & 305 & 319 \\
\hline \multicolumn{5}{|l|}{ Desmopressin $2 \mu \mathrm{g}$} \\
\hline$+3 \mathrm{~h}$ & 304 & 127 & 309 & 437 \\
\hline$+7 \mathrm{~h}$ & 299 & 155 & 306 & 418 \\
\hline$+24 h$ & 321 & 376 & 300 & 358 \\
\hline \multicolumn{5}{|l|}{ Day 2} \\
\hline \multicolumn{5}{|l|}{ Desmopressin $20 \mu \mathrm{g}$} \\
\hline$+3 \mathrm{~h}$ & & & 297 & 444 \\
\hline$+7 h$ & & & 293 & 458 \\
\hline
\end{tabular}

comparison to normal responses are given in Figure 1. In the initial study, plasma osmolality rose from a basal value of 298 to $322 \mathrm{mOsm} / \mathrm{kg}$ and was associated with a rise in plasma vasopressin concentration from 0.8 to $9.2 \mathrm{pmol} / \mathrm{l}$. Linear regression analysis applied to these variables defined the function $\mathrm{pAVP}=0.27$ (pOsm-301), $\mathrm{r}=+0.75, P<0.05$, where pAVP and pOsm represent plasma arginine vasopressin and plasma osmolality, respectively. Thirst was sensed as the infusion proceeded and then increased in a progressive linear manner (Figure 1). Linear regression analysis defined the function $\mathrm{Th}=0.16$ (pOsm302), $\mathrm{r}=+0.94, P<0.01$.

The repeat study performed one year after stopping lithium showed similar results. Plasma osmolality rose from 308 to $330 \mathrm{mOsm} / \mathrm{kg}$ associated with a rise in vasopressin from 0.5 to $7.0 \mathrm{pmol} / \mathrm{l}$. The vasopressin regression function was pAVP $=0.32$ (pOsm-308), $\mathrm{r}=+0.96, P<0.001$, and the thirst regression function, $\mathrm{Th}=0.43$ (pOsm-306), $\mathrm{r}=+0.98, P<0.001$.

Results of desmopressin administration on urine osmolality are given in Table I. Maximum urine osmolality (458 mOsm $/ \mathrm{kg}$ ) failed to achieve normal maximal values $(>650 \mathrm{mOsm} / \mathrm{kg}$ for elderly patients) following desmopressin during initial studies and after 1 year without lithium.

\section{Discussion}

Our results demonstrate that this patient had two major abnormalities; one was partial nephrogenic diabetes insipidus identified by the failure to concentrate urine despite large doses of desmopressin, and the other was a change in the 'set' of her osmostats for both thirst and vasopressin release. On the two occasions that she was osmotically stimulated there was clear evidence that she remained hypodipsic until plasma osmolality rose to extraordinary values. Basal plasma vasopression was always inappropriately low in comparison to basal plasma osmolality, but did rise in a progressive manner as plasma osmolality was increased. The regression lines for vasopressin and osmolality generated from data obtained from infusing hypertonic saline on the two occasions had normal slopes ranging from 0.27 to 0.32 , but the abscissal intercepts were distinctly elevated at 301 and $308 \mathrm{mOsm} / \mathrm{kg}$ compared to normal (see Figure 1). The slope of the regression line has been described as the sensitivity of the osmoreceptor/vasopressin-releasing unit while the abscissal intercept describes the theoretical threshold for vasopressin release. ${ }^{14}$ Thus there appears to be a resetting of the osmostat for vasopressin release to values higher than normal. Applying a similar established method to analyse the data on thirst, there was a shift in the thirst threshold to abnormally high plasma osmolality values, 302 and $306 \mathrm{mOsm} / \mathrm{kg}$.

The change in the set of osmostats for thirst and vasopressin release accounts entirely for the patient's chronic hypernatraemia. She osmoregulated around a higher than normal set-point. This is a most unusual osmoregulatory pattern in chronic hypernatraemia, which has been reported only once before in a young woman with multiple congenital abnormalities and hypothalamic defects. ${ }^{8}$ Other reports have suggested or described normal osmotic thresholds for vasopressin release but reduced sensitivities or slopes of the osmotic regression line, combined with hypodipsia., ${ }^{3,9}$

This patient's disorder is complicated by partial nephrogenic diabetes, which fortunately is mild, and she only becomes markedly polyuric when attempts are made to lower plasma sodium or osmolality to normal. She can therefore readily excrete solute-free water. Although she is hypodipsic at her 'normal' plasma osmolalities she is protected from progressive hypernatraemia and dehydration by her thirst which drives her to drinking, but at higher than normal plasma osmolalities.

It is very likely that the partial nephrogenic diabetes insipidus is due to her chronic lithium therapy ${ }^{15}$ as no other cause could be established to account for the 
polyuria. Usually, however, stopping lithium therapy allows the return of normal renal concentrating ability within a few weeks, ${ }^{16}$ although it is recognized that some patients develop persistent and occasionally progressive renal lesions. ${ }^{17,18}$

More speculative is the cause of the reset osmostat. High definition CT scanning of the anterior hypothalamus, the putative site for these osmoreceptors, appeared to be entirely normal and function of the anterior pituitary was unremarkable. It seems unlikely that she had a large structural abnormality in the hypothalamo-pituitary area. Since she had hypertension it is possible that she might have suffered a small, very localized infarct affecting the function of the osmoreceptors. However at no stage did she ever exhibit any abnormal neurological features. An alternative explanation could be the lithium therapy. The

\section{References}

1. Avioli, L., Earley, L.E. \& Kashima, H.K. Chronic and sustained hypernatraemia, absence of thirst, diabetes insipidus and adrenocorticotrophin insufficiency resulting from widespread destruction of the hypothalamus. Ann Int Med 1962, 56: 131-140.

2. Sridhar, C.B., Calvert, G.D. \& Ibbertson, H.K. Syndrome of hypernatraemia, hypodipsia and partial diabetes insipidus: a new interpretation. $J$ Clin Endocrinol Metab 1973, 38: 890-901.

3. De Rubertis, F.R., Michelis, M.F. \& Davis, B.B. "Essential hypernatraemia". Arch Int Med 1974, 134: 889-895.

4. Halter, J.B., Goldberg, A.P., Robertson, G.L. \& Porte, D. Selective osmoreceptor dysfunction in the syndrome of chronic hypernatraemia. J Clin Endocrinol Metab 1977, 44: 609-616.

5. Gossain, V.V., Kinzel, T., Strand, C.V. \& Rovner, D.R. Essential hypernatraemia. Am J Med Sci 1978, 275: 253258.

6. Brezis, M. \& Weiler-Ravell, D. Hypernatraemia, hypodipsia and partial diabetes insipidus: a model for defective osmoregulation. Am J Med Sci 1980, 279: 37-45.

7. Dunger, D.B., Lightman, S., Williams, M., Preece, M.A. \& Grant, D.B. Lack of thirst, osmoreceptor dysfunction, early puberty and abnormally aggressive behaviour in two boys. Clin Endocrinol 1985, 22: 469-478.

8. Gill, G., Baylis, P. \& Burn, J. A case of "essential" hypernatraemia due to resetting of the osmostat. Clin Endocrinol 1985, 22: 545-551.

9. Robertson, G.L. The pathophysiology of ADH secretion. In: Tolis, G., Labrie, F., Martin, J.B. and Naftolin, F. (eds) Clinical Neuroendocrinology: a Pathophysiological Approach. Raven Press, New York, 1979, fact that the disorder failed to resolve after stopping lithium does not necessarily militate against this explanation, as permanent damage to other tissues has been demonstrated previously. ${ }^{18}$ However, it should be $\overline{\text { जे }}$ emphasized that the majority of patients who aretreated with lithium show a reversible steepening of $\frac{}{0}$ the slope to the osmoregulatory regression line for $\overline{\bar{c}}$ vasopressin or increase in sensitivity to vasopressin $\widehat{\nabla}$ release, and not a change in set for vasopressin release and thirst. ${ }^{19}$ Thus, although there are a variety of ${ }^{\infty}$ possible explanations, the precise cause of the reset $\vec{O}$ osmostat must remain speculative.

\section{Acknowledgement}

The work was supported by funds from the Scientific and 3 Research Committee, Newcastle Health Authority. CJT is a $\dot{\sigma}^{\circ}$ M.R.C. Training Fellow.

247-260.

10. Hammond, D.N., Moll, G.N., Robertson, G.L. \& Chelmicka-Schorr, E. Hypodipsic hypernatraemias with nor- $O$ mal osmoregulation of vasopressin. $N$ Engl J Med 1986, 315: 433-436.

11. Baylis, P.H. \& Robertson, G.L. Infusion of hypertonic saline to assess posterior pituitary function in polyum patients. J R Soc Med 1980, 73: 255-260.

12. Thompson, C.J., Bland, J., Burd, J. \& Baylis, P.H. T医. osmotic thresholds for thirst and vasopressin release similar in healthy man. Clin Sci 1986, 71: 651-656.

13. Rooke, P. \& Baylis, P.H. A new sensitive radioimmunoassay for plasma arginine vasopressin. $J$ Immunoassay 1982, 3: 115-131.

14. Baylis, P.H. Posterior pituitary function in health and $\stackrel{\mathbb{Q}}{\unrhd}$ disease. Clin Endocrinol Metab 1983, 12: 747-770.

15. Baylis, P.H. \& Heath, D.A. Water disturbances in patients treated with oral lithium carbonate. Ann Int Med 1978, 88: 607-609.

16. Baldessarini, R. \& Lipinski, F. Lithium salts $1970-75$. Ann Int Med 1975, 83: 527-533.

17. Simon, N.M., Garber, E. \& Arrieff, A.J. Persistent nephrogenic diabetes insipidus after lithium carbonate. Ann Intern Med 1977, 86: 446-447.

18. Walker, R.G., Escott, M., Birchall, I., Dowling, J.P. \& Kincaid Smith, $\mathbf{P}$. Chronic progressive renal lesions induced by lithium. Kidney Int 1986, 29: 875-881.

19. Gold, P.W., Robertson, G.L., Post, R.M. et al. The effect of lithium on osmoregulation of arginine vasopressin secretion. J Clin Endocrinol Metab 1983, 56: 295299. 